Author: J Ridl \& E Couzens

MISPLACING NEMA? A CONSIDERATION OF SOME PROBLEMATIC ASPECTS OF SOUTH AFRICA'S NEW EIA REGULATIONS

2010 VOLUME 13 No 5 


\title{
MISPLACING NEMA? A CONSIDERATION OF SOME PROBLEMATIC ASPECTS OF SOUTH AFRICA'S NEW EIA REGULATIONS
}

\author{
J Ridl ${ }^{*}$ and E Couzens**
}

\section{Introduction}

On 21 April 2006, South Africa's then Minister of Environmental Affairs and Tourism, Marthinus van Schalkwyk, published Environmental Impact Assessment ${ }^{1}$ Regulations ${ }^{2}$ in terms of Chapter 5 of the National Environmental Management Act $^{3}$ along with lists of activities and competent authorities identified in terms of Sections 24 and 24D of NEMA. ${ }^{4}$ In announcing their imminent publication, the Minister pronounced them to be "quicker, simpler, better". 5 This article will examine this statement in the context of the content of the new Regulations and what purports to address the shortcomings perceived in the old Regulations. ${ }^{6}$ In so doing, criticisms of the old Regulations will be examined in an attempt to show that, unless the reasons for the failures of the old Regulations are considered and dealt with, the new Regulations will suffer a similar fate. ${ }^{7}$ Finally, and critically, it will be argued that the

Jeremy Ridl. BA LLB LLM Environmental Law (Natal) PhD (Regent). Attorney, South Africa. Environmental Law specialist (jaridl@absamail.co.za). Member of the Interim Certification Board for Environmental Assessment Practitioners. Member of the Institute of Waste Management.

** Ed Couzens. BA Hons LLB (Wits) LLM Environmental Law (Natal \& Nottingham) PhD (KZN). Attorney, South Africa, and Associate Professor, Faculty of Law, University of KwaZulu-Natal, South Africa (couzense@ukzn.ac.za). We wish to thank the PER's anonymous reviewers for their helpful comments. In late 2010, too late for consideration in this article, two events of significance to the present subject matter occurred:

(a) On 2 August 2010, revised Environmental Impact Assessment Regulations came into force. (See for instance, LED SALGA $2010 \mathrm{http}: / / \mathrm{bit} . \mathrm{ly} / \mathrm{hBg} 7 \mathrm{HU}$.) The revised Regulations brought into force were published in GG 33306 of 18 June 2010.

(b) On 31 October 2010, Minister of Water and Environmental Affairs Buyelwa Sonjica was replaced as Minister by Edna Molewa, previously Minister of Social Development.

Hereafter EIA.

GN R385 in GG 28753 of 21 April 2006.

107 of 1998 - hereafter NEMA.

GN R386 in GG 28753 of 21 April 2006 and GN R387 in GG 28753 of 21 April 2006, respectively.

5 Van Schalkwyk 2006 http://bit.ly/fsdco5 and Van Schalkwyk 2006 Mail \& Guardian 21. "Simpler, better, greener" were the words used in the title of Van Schalkwyk's article.

6 The lists of activities to which the regulations apply are contained in GN R1182 in GG 18261 of 5 September 1997.

7 The new Regulations came into force on 1 July 2006 (1 April 2007 for mining operations). At the time of promulgation of the new Regulations, some 3000 EIAs nationally remained to be determined under the old Regulations. In addition, for years to come there will be disputes over EIAs conducted under the old Regulations, which disputes will require perusal of the old 
fundamental principles of NEMA and the elements that arguably place it far above equivalent legislation elsewhere in the world have been largely ignored.

\section{The old Regulations}

When the old Regulations emerged from the draft that had preceded them, they were a streamlined version, so distilled that they were almost cryptic. ${ }^{8}$ Instead of everything being spelt out "chapter and verse", it was left to environmental consultants and government to add content in the application of the law. The Regulations themselves provided a broad framework within which the principles of integrated environmental management ${ }^{9}$ were to be applied. These principles were not articulated in any statute, but were well understood by the then growing body of EIA practitioners as the right way to go about environmental decision-making. The concept was succinctly described in a document published by the Council for the Environment. ${ }^{10}$ This was substantially revised by the Department of Environmental Affairs in 1992. ${ }^{11}$ The latter version consisted of six volumes and formed the basis for the draft Regulations that spelt out, carefully, the procedures, the categorisation of activities and different processes to be adopted, depending on the complexity of the environmental issues involved. This "omnibus" version that included the important, but impracticable, provisions relating to the certification or accreditation of practitioners was trimmed to about eight pages in the Gazette. The new Regulations exceed fifty pages, so it seems that we have come full circle. The sheer size of the new Regulations may make them inherently unwieldy. However, it is the content and the practicability of the Regulations that is important, not their size.

Regulations to determine whether they were properly conducted. The old Regulations are not history yet and comment on them at this stage still has relevance and value.

8 For descriptions of EIA in South Africa in general, see Peckham 1997 SAJELP 113; Glazewski Environmental Law 230-231; Kidd Environmental Law 195-206; Aucamp 2009 Environmental Impact Assessment; and Kidd and Retief "Environmental assessment".

Hereafter IEM.

Council for the Environment Integrated Environmental Management.

For an examination of the link between IEM and EIA, see Ridl 1994 SAJELP 62-64. For the original Council for the Environment publication, see Council for the Environment Integrated Environmental Management. For the Department of Environment Affairs (hereafter DEA) revision, see DEA Guidelines. 


\section{$3 \quad$ Ideological shift}

There has been an ideological shift in the development of environmental decisionmaking in the metamorphosis of EIAs. Prior to the promulgation of the old Regulations, EIAs were undertaken voluntarily, usually to appease public demand therefore to satisfy investing companies in countries with more stringent environmental standards, or even in the genuine interest of wise use of natural resources. Mordant critics of big business suggest that the voluntary assumption of IEM was no more than "green washing" ${ }^{12}$ to conceal environmental malpractices, ${ }^{13}$ and that, in the era of the old Regulations, the process enjoyed little public trust because it was manipulated to suit developer needs, poorly managed by consultants and inconsistently adjudicated. ${ }^{14}$ Environmental impact assessments are often undertaken simply because they are legally required, not because their purpose is seen as being valuable. They are seen as producing delays, not wise resource use. $^{15}$

These are clearly serious criticisms, be they perception or reality. Until EIA regains the support of all participants in the process and inspires public confidence in its results, its value as a tool in environmental decision-making will be minimal. Moreover, unless officials who have the responsibility to control the process are made to feel less vulnerable to attack, both in their official and personal capacities, their present response, generally to confess to a lack of departmental capacity and to avoid making decisions, will continue. Some form of quality assurance of

12 The term "green washing" might be explained as a cynical description of efforts made by large corporations or similar entities to appear more environmentally conscious than they are, especially through misleading advertising.

13 Ridl 1994 SAJELP61.

14 See Field 2005 SALJ 761, in which she observes:

[l]f public perception is indeed 'wrong' as the scientists claim, and if public opinion is so susceptible to being led astray by public interest organizations with ulterior motives, then surely public participation is environmental decision-making is more of a nuisance than a need?

She argues that public participation is a sine qua non to the "paradigm of sustainable development to which South Africa is committed" and that the matter is therefore beyond debate.

15 See Couzens and Gumede 2007 SAJELP 125 and in particular their concerns about the perception of senior members of government of EIA as an obstacle to development. The facts of the case under discussion underscore the inherent lack of trust that exists between environmental NGOs and environmental officials. 
environmental practitioners is required to enable their profession to regain its integrity and its reputation for independence and objectivity. ${ }^{16}$

\section{A teleological approach to environmental impact assessment}

It is necessary to recognise the shift of the essence of EIA, in order to facilitate a better understanding of its purpose separate from its social, environmental and political causes (in other words, considered "teleologically", to ascertain the intention of the designer/s of the EIA process). Prior to the provision of mandatory EIA, strategic business decisions were determined by two factors: technical feasibility and financial viability. Environmental considerations were largely excluded. As fears of the environmental consequences of commercial and industrial activities grew, recognition was given to the need for environmental controls, even if this was to ensure the sustainability of resources for their commercial value, not for the altruistic purpose of "caring for the earth". ${ }^{17}$ In advocating the inclusion of environmental considerations into the development equation, ${ }^{18}$ a "biological approach" was advocated. ${ }^{19}$ The importance of a holistic understanding of all of the implications of development for the receiving environment was emphasised, in particular the synergies of its interrelated parts. ${ }^{20}$ Integrated environmental management recognises these concepts. ${ }^{21}$

In parallel with this shift in environmental thinking, social priorities in urgent need of attention were brought into the mix, and produced the complex matrix that underpins the primary purpose of EIA: creating and maintaining the delicate tripartite balance

16 The new Regulations do not deal with the control over or accreditation of environmental practitioners. See the discussion on this below, under S 12.

17 IUCN et al Caring for the Earth. The aim of the strategy is to improve the condition of the world's people by defining two requirements: the securing of a widespread and deeply held commitment to a new ethic, the ethic for sustainable living, and to translate its principles into practice; and the integration of conservation and development so that human actions are kept within the Earth's capacity.

Jain et al Environmental Impact Analysis 18.

See Ward Biological Environmental Impact Studies.

Ward Biological Environmental Impact Studies 10.

See DEAT Environmental Impact Reporting. More detailed references to this work will be cited with reference to the series number in which it appears. The series (seventeen volumes) is a useful compendium of material providing a better understanding of the technical aspects of EIA. Very little of the conceptual material, in particular that contained in Information Series 3: Stakeholder Engagement, appears to have been taken into account in formulating the rules for public participation in the regulations. 
between economic benefits, social upliftment and environmental integrity, in short, "sustainable development" as it is defined in Sections 2(3) and 2(4) of NEMA. To achieve this purpose, a huge challenge is posed to both the EIA process and its participants. Just how difficult this is may not be fully understood; and criticism of the process and the role-players may be born out of ignorance. ${ }^{22}$

\section{The right to an environment that is not harmful to health or well-being}

Section 24 of the Constitution ${ }^{23}$ is generally interpreted to mean that the so-called "environment right" is created and included in the Bill of Rights. ${ }^{24}$ There has been considerable debate on the meaning of Section 24(a) and the reason that it is expressed in negative terms. It goes beyond the ambit of this examination to add to the debate, save to the extent that it must be understood if it is to be applied in EIAs. The promulgation of NEMA and the new Regulations is clearly a response by the government to Section 24(b) of the Constitution. If a teleological approach is to be followed, then EIA must be judged on its contribution to the attainment by everyone of his/her environmental right, by which is meant an environment that is not harmful to his/her health or well-being, for surely this is its fundamental purpose. Secondary to this human right is the protection of the environment for its intrinsic worth. ${ }^{25}$

The emphasis in most EIAs in South Africa has been on the first element of the environmental right. "Health" in the constitutional context is determined and measured biophysically and objectively. A "healthy environment" is one that is in ecological balance and "human health" is indicated by the presence or otherwise of a clinically diagnosable medical condition. "Well-being" is something quite different. It

22 The enormity of the task is probably one of the reasons that many EIAs have fallen short of assessment proper even when this has been crucial to the decision-making process. See further discussion on this below.

23 Constitution of the Republic of South Africa, 1996 - hereafter Constitution.

24 This should not be interpreted to mean that the environment itself has rights, but that, as a fundamental human right, one is entitled to live and work in a safe environment.

25 This interpretation will not find favour with environmentalists. However, it is consistent with the peremptory assertion in S 2(2) of NEMA that environmental management "must put people and their needs at the forefront of its concern". 
is esoteric, subjective and difficult to quantify. ${ }^{26}$ It is in this latter respect that EIA becomes most complex; and where it has, perhaps predictably, failed.

\section{General criticisms of the old Regulations}

In Minister Van Schalkwyk's press release announcing the imminent promulgation of the new Regulations, the claim was made that they are "quicker, simpler, better". In the same press release, however, the Minister immediately contradicted himself. $\mathrm{He}$ praised the old Regulations for the contribution they had made to assisting the authorities to make informed decisions about development activities, developers to save money, communities to be heard, and "most crucially, [to having] ensured that the negative impacts on our environment and on human health are proactively identified, prevented or managed". ${ }^{27}$ If this were true, there would have been no reason for change.

In diagrammatic form, the old Regulations can be represented as follows:

Structure of an EIA:

(a) Application for authorisation

(b) Plan of study for scoping

(c) Scoping study

(d) Scoping report

(e) Review of scoping report by authorities and the public:

(aa) Possible authorisation, if no problems foreseen

(bb) If problems foreseen, then:

(i) Plan of study for EIA

(ii) Specialist studies and assessment

(iii) EIA report

(iv) Review by officials and public

(v) Authorisation or refusal

26 Probably the best clue to the meaning of "well-being" is to be found in S 2(2) of NEMA, which details a cluster of interests that must be served by environmental management: "physical, psychological, developmental, cultural and social".

27 MacLeod $2006 \mathrm{http}: / / \mathrm{bit} . \mathrm{ly} / \mathrm{if07ZJ}$. 
(cc)

Appeal, if refusal ${ }^{28}$

In summary, the Minister makes the following criticisms of the old Regulations: a lack of (procedural) clarity has led to inconsistent application of the law, the procedure is inflexible, time delays have plagued the process, there is a lack of guidance in the public participation process, reports of poor quality and bias have undermined faith in the concept of "EIA", and that the old system "triggered" far too many EIAs.

The Minister saw the need to align assessment with our "much-evolved environmental management law" so that "our environmental laws are more efficient and effective". The Minister's comments are probably reflective of a general perception of the failings of EIA. ${ }^{29}$ This perception is correct in that EIA has (strongly arguably, despite a lack of sound empirical data to support the point) failed to a large degree to serve the purpose of sound, participative environmental decision-making. However, the reasons for its failure are not properly understood. There is a significant danger that the new Regulations will suffer a similar fate, and that they too will quickly be blamed for delays in the development process. Environmental impact assessments will again become the scapegoat for government's lack of delivery in key areas such as housing, water and sanitation, electricity provision and job creation. ${ }^{30}$ Central to the success of EIAs are proper application of the Regulations that govern the process and an understanding of the legal framework within which they are applied. The failings in the old Regulations should be kept in mind, and referred to when necessary, as a backdrop to evaluation of the improvements (if any) made by the new Regulations. Areas for potential failure of the new Regulations owing to many of the same flaws that dogged the old Regulations will be highlighted in the next section.

28 Summary of Environment Conservation Act 73 of 1989 (hereafter ECA), GN R1182 in GG 18261 of 5 September 1997, GN R1183 in GG 18261 of 5 September 1997 and GN R1184 in GG 18261 of 5 September 1997. See Ridl, Carnelley \& Couzens 2005 SAJELP 160-162.

29 For examples of this perception, see Couzens and Gumede 2007 SAJELP.

30 See MacLeod $2006 \mathrm{http} / / / \mathrm{bit}$. ly/if07ZJ. The President's statement only a month after the promulgation of the new Regulations that green laws were causing development delays and had contributed to the slowing down of economic activity does not augur well for their future role in ensuring sustainable development. It also contradicts the assurances given by Minister Van Schalkwyk 2006 Mail \& Guardian that there was no weakening of the government's commitment to the EIA process. 


\section{The new Regulations}

In diagrammatic form, the new Regulations can be represented as follows:

Environmental assessment, the new procedure (from 1 July 2006):

(a) Environmental assessment practitioner ${ }^{31}$ appointed

(b) Environmental assessment practitioner reviews and decides whether a basic assessment or a full environmental assessment is required

(A) If a basic assessment is decided on:

(a) The assessment is conducted:

(i) A basic assessment report is compiled

(ii) Application is made to the competent authority

(iii) Possible revision of documents

(b) Decision to grant/refuse application

(c) Appeal procedure, if application granted/refused

(B) If a full environmental assessment is decided on:

(i) A plan of study for an EIA is prepared and submitted

(ii) The scoping report is conducted

(iii) The scoping report and plan of study are considered

(iv) Approval is required at this stage

(v) With approval, an EIA is performed

(vi) An environmental impact report ${ }^{32}$ is compiled

(vii) Application is made to the competent authority

(viii) An opportunity for revision might be granted

(a) Environmental authorisation granted/refused

(b) Appeal procedure ${ }^{33}$ 


\section{$8 \quad$ Time limits and delays under the old Regulations}

While the old Regulations did not fix specific time limits, ${ }^{34}$ these could be set at the inception of the process by agreement (and even included in the approved plan of study for scoping) between the applicant and the authorities and, once fixed, would be binding on interested and affected parties. ${ }^{35}$ The logic of this approach was to give the process flexibility and to determine time-frames dependant on the complexity of the anticipated issues, a decision best made by the authority in consultation with the EAP. Usually, however, the provisions of Regulation 3(5) were largely ignored and no time-frames for the different components of the process were set. As a result, the response times expected from the authorities, and from I\&APs, were vague and unenforceable. ${ }^{36}$ This was not a failing of the law but rather neglect on the part of EAPs and the authorities to recognise the obligation on them to fix time limits and to make these known to I\&APs.

The lack of fixed time limits in the old Regulations was only one of the reasons for the delays encountered in the completion of some EIAs. In many EIAs, the issues that must be identified, evaluated and assessed are extremely complex and may require the input of specialists who might not be readily available. ${ }^{37} \mathrm{~A}$ long and slow process might therefore be both inevitable and justified. ${ }^{38}$ In such a case, time limits must be approached realistically and there must be a clear disclosure, or mapping out, of the process at the outset. It is also important that the various participants accept both the role they are to play and the time-frames within which they will have

34 Except in Reg 11(1) that requires an appeal to be lodged within thirty days of the issue of the record of decision (hereafter ROD).

35 Hereafter I\&APs. Reg 3(5) provides: "Any interested party who wishes to participate in the public participation process contemplated in sub-regulation $1(\mathrm{f})$ must respond with the time agreed to between the relevant authority and the applicant". While a time limit is not specified, both the applicant (Reg 3(1)(d)(iv)) and the relevant authority (Reg 3(3)(a)(iii)) have the ability to "timeously produce thorough, readable and informative documents". Once "agreement" has been reached and compliance with the time-frames fixed, "timeously" in the context of the subregulation is given meaning.

36 This is something that may yet remain the case, given the lack of capacity in, especially, local government.

37 For example, an EIA for development of a large tract of land that is known to be (or is suspected to be) rich in palaeontological or archaeological resources will require the services of one of only a few experts in this discipline in private practice, and the field work may be very timeconsuming.

38 If the study involves the identification of vegetation or migrant birds, a proper assessment may only be possible if the site is studied in all four seasons. No fast-track approach is possible in such circumstances. 
to operate. Too frequently, the expectations of the developer on the one hand, and the demands of I\&APs on the other, are poles apart. ${ }^{39}$ The process fails if the EAP and the authority are unable to bridge this gap. Conversely, unless there is at least some trust in the process itself, there will be no mechanism to bring the parties together. ${ }^{40}$ The impasse that results is a major cause of delay.

\section{$9 \quad$ Time limits under the new Regulations}

The fixing of time limits under the new Regulations may be perceived as a longoverdue solution to the vexed issue of delay in the completion and consideration of EIAs. The new Regulations do indeed fix time limits; but these are triggered only a long way down the process. The causes of the delays that plagued the scoping and assessment phases of the old Regulations are not addressed in the new Regulations. ${ }^{41}$ As a result, the challenge of ensuring a speedy but complete and adequate process will still rest with the participants.

\subsection{Identification of activities}

Closely linked to the imposition of time limits is the identification of activities and the determination of processes applicable to such activities. ${ }^{42}$ At the most simple level is a "basic assessment" determined by the EAP in terms of Regulation 20(1), read with Regulation 21, which relates to activities that are considered to have a lower

39 For many developers, the need for an EIA is seen as a nuisance - red tape that must be cut through. They do not see it as adding value to their development. On the other hand, I\&APs may see the process as one that is there to ensure that their wishes prevail, irrespective of the merits of the proposed development and its potential benefits to society at large.

40 It has been suggested that alternative dispute resolution (conciliation, mediation, arbitration; hereafter ADR) lends itself to the settling of environmental disputes, and indeed it has outside of South Africa. In South Africa, without some coercive force to bring the parties to the table, it has been used rarely with success. Chp 4 of NEMA provides comprehensive provisions for "fair decision-making and conflict management", but this legislation too, has been largely ignored by parties to environmental disputes. In making a strong case for the use of ADR in the case study reviewed, Couzens and Dent 2006 PER do not explain the manner in which the parties can be brought to the table in order to engage in settlement discussions. The authors implore the various parties to apply ADR but do not suggest the manner in which this will happen without consensus. Without the intervention of the Minister, Member of the Executive Council (hereafter MEC) or Municipal Council, S17 of NEMA lies fallow. The authors do contend that, in the case under discussion, a duty to apply ADR was ignored.

41 It may be that the new Regulations will prove as difficult to enforce as were the old. One danger is that authorities might consider the time-frames as deadlines - and not as time-frames within which decisions should be taken.

42 See below under S 12. 
environmental impact. The more complex assessment requires scoping and the submission of a full EIA report. In determining the level of investigation to be undertaken, there is the assumption that the potential impacts, by their magnitude, will indicate the more comprehensive approach and, it follows, more time-consuming process. As will be observed infra, the magnitude of an activity may in itself indicate a high level of significance; ${ }^{43}$ but that an activity of low magnitude (determined biophysically) has low significance is not necessarily the corollary. The setting of thresholds that indicate levels of significance is something that is not adequately addressed in the new Regulations. The EAP is entrusted with the determination by applying the criteria set out in Regulation 21, of which process is to be followed. The guidelines are relatively straightforward, but the lists of activities are capable of differing interpretations, and there may be disagreement as to which procedure is to be followed. Where doubt exists, the precautionary principle ${ }^{44}$ should be adopted and the scoping and environmental assessment route should be followed. However, too ready a departure from basic assessment in favour of scoping and environmental assessment should not be allowed to defeat the object of providing a more streamlined process, if such streamlining is appropriate..$^{45}$

\subsection{Receipt of application for authorisation}

The authority must acknowledge receipt of an application for authorisation within fourteen days if the application is in order, or reject it if it is not within the same period. ${ }^{46}$ The Regulations do not provide a mechanism for proving delivery to the authority (receipt), from which date the acknowledgement of receipt must be formally provided. The authority would be acting within its rights to refuse to acknowledge

43 "Significance" as a concept is at the core of environmental decision-making and is used frequently in environmental legislation in the context "and which may significantly affect the environment". It is defined in the new Regulations thus: "significant impact" means an impact that "by its magnitude, duration, intensity or probability of occurrence may have a notable effect on one or more aspects of the environment". It is beyond the scope of this article to consider the concept in more detail. For a detailed treatment of the topic, see DEAT Information Series 10: Strategic Environmental Assessment

44 Although the precautionary principle as envisaged in much international environmental thinking is not formally present in South Africa's legislation, NEMA does contain a formulation of it (the "risk averse and cautious approach") in S 2(4)(1)(vii).

45 This will require both competence and integrity on the part of the EAP and willingness on the part of the authority to promote a speedy conclusion to the assessment process. The objection might also be made that "basic" and "full" reports are inherently similar - and that the better distinction would be between "assessing" and "scoping".

46 Reg 14(2). 
receipt, as this would signify acceptance of the application prior to the authority having applied its mind to its technical correctness. Conceivably, the authority might, perhaps through inefficiency, do nothing to acknowledge delivery of the application to it and the fourteen-day period would arguably then not commence.

\subsection{Consideration of the application}

If receipt of the application is acknowledged in terms of Regulation 14(2), the authority must consider the application within thirty days of such acknowledgement. ${ }^{47}$ Within this period, the authority may reject the application, request more information, request specialist input, suggest alternatives be considered, or request scoping and assessment. ${ }^{48}$ If the application does not comply with Regulation 23 , or if it is based on an insufficient public participation process, it may be rejected. ${ }^{49}$ If more information, specialist input, the consideration of alternatives, or scoping and assessment are requested, the application is reconsidered and the thirty-day period commences afresh from the date of submission of the information requested. If scoping and assessment are requested, then the application is considered under Regulations 30 to $36 .{ }^{50}$

\subsection{Public participation process}

Prior to the submission of a basic assessment that must accompany an application for authorisation, a public participation process must be undertaken in accordance with Regulation 56. ${ }^{51}$ No time limits are fixed with regard to any part of the public participation process, be it the period within which I\&APs must respond to notices, consider reports or file comments on any documents provided during the course of the process. Regulation 55(6) merely requires that I\&APs be provided with information and with a "reasonable opportunity"52 to comment on the application. The person conducting the public participation process (who is not necessarily the

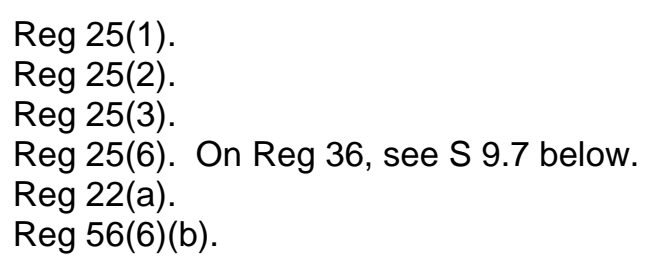


EAP and may not have the same constraints that are imposed on EAPs by the Regulations) ${ }^{53}$ must ensure that:

(a) information containing all relevant facts in respect of the application is made available to potential interested and affected parties; and

(b) participation by potential interested and affected parties is facilitated in such a manner that all potential interested and affected parties are provided with a reasonable opportunity to comment on the application.

The fixing of time limits for the public participation process, accordingly, lies solely in the hands of the applicant. The applicant may choose not to use the EAP for the public participation process. Since no definite guide is provided for what constitutes "a reasonable opportunity to comment on the application", this is left to the discretion of the applicant - hopefully, accepted practice will develop in this regard. No mention is made of any requirement to hold public meetings, ${ }^{54}$ nor is there any requirement for consultation or dialogue in any form. The rights of I\&APs are limited to "comment". 55

\subsection{A retrogressive step}

In this respect, the new Regulations are arguably a retrogressive step. As observed above, the old Regulations required time limits in respect of all aspects of the process to be fixed by the applicant and the authority. ${ }^{56}$ Furthermore, in the setting of time periods for the different components, the authority is required to "try to keep the inputs required by the applicant to the minimum that are necessary to make an informed decision on the application, without putting any limitation on the rights that

53 Regs 17-19 (in particular, the requirements in Reg 18 that the EAP be independent, objective, competent and generally behave in an ethical manner). The "person" referred to in Regulation 55(6) could be the in-house public relations officer of the applicant and could manipulate the information provided and the way in which it is presented to favour the applicant. There appears to be no bar to this in the Regulations.

54 Reference is made to provision of the minutes of "any meeting held" between I\&APs and the EAP or applicant in Reg 24(b)(iii) to accompany the basic assessment report, in Reg 30(b) to accompany the environmental assessment report, and in Reg 57(1)(a) in the compilation of a register of I\&APs. However "meeting" as a component of public participation is not mentioned.

55 "Public participation" as defined in the new Regulations is different to the original understanding thereof when the concepts of "integrated environmental management" and "EIA" were introduced to South Africa in the early 1980s. This change and the reasons therefore will be examined below.

56 Reg 3(5). 
interested parties may have in terms of these regulations". ${ }^{57}$ While the vagueness of the old Regulations may have created difficulty in the enforcement of the provisions relating to the fixing of time limits, ${ }^{58}$ if the applicant did meet the authority and did agree to time-frames, these became legally binding not only on the parties thereto, but, by the application of Regulation 3(5), on I\&APs too. Consequently, criticisms of the Regulations for their failure to manage time-frames adequately and that they in fact "caused development delays"59 are misdirected. The fault lies directly with the authorities and with the applicants for not fixing the time limits in advance of the process, and for not notifying I\&APs of the time limits applicable. ${ }^{60}$ In the absence of time limits, the public participation process becomes difficult to manage, particularly with regard to holding I\&APs to reasonable time-frames for responses. Without a mechanism to compel responses, or at least to have a failure to respond declared a waiver of the right to do so, many EIAs have in the past simply become bogged down. 61

\subsection{Arbitrary nature of time-frames}

The time limits set in the new Regulations appear on the face of it to be inordinately short, ${ }^{62}$ or are at least arbitrary. The language of the new Regulations when defining time limits is peremptory; and, therefore, the time limits set are mandatory. This is at variance with the provisions of Regulation 9, which states that "[a] competent authority must strive to meet timeframes applicable to competent authorities in terms

$57 \operatorname{Reg} 3(3)(d)$.

58 It might be argued that "vagueness" allows for "flexibility" - but in this case, it appeared rather to create problematic uncertainty.

59 Words attributed to President Mbeki in MacLeod 2006 http://bit.ly/if07ZJ.

60 From a practical point of view, it may be difficult for the authority to commit to time-frames during the EIA phase, since it is only during scoping that the full complexity of the issues will be identified. This is not however a bar to fixing time-frames for the critical scoping phase; and, on completion thereof, setting the time-frames for the phase that follows.

61 According to DEAT $2006 \mathrm{http} / / / \mathrm{bit}$.ly/hbqAP8, the provinces received a total of 43423 applications for EIA authorisation between September 1997 and March 2006 . Of these applications, 35536 have been finalised and 3097 withdrawn. This means that at least 4790 applications are still current. These current applications fall into three categories: dormant applications (authorities await action from the applicant), applications awaiting authority action (still within reasonable time-frames), and backlog (applications awaiting action and being delayed by authorities).

62 No account is taken of the capacity of the various authorities to comply with these new timeframes. It widely held that a primary cause of delays under the old Regulations was the lack of capacity and skills of the authorities and that this will continue to plague the new Regulations. No credible response to this has been provided to this criticism. The Minister's response (see MacLeod $2006 \mathrm{http}: / /$ bit.ly/if07ZJ) is that capacity and skills will be put in place by holding oneday information seminars across the country. Clearly, the Minister is out of touch with the magnitude and depth of the problems that have been encountered in EIA. 
of these Regulations [own emphasis]". It would appear that strict compliance will be required of all of the applicants, EAPs and I\&APs, but that some latitude will have to be tolerated with the authorities. This is more a matter of practicality than of law. It is unrealistic to expect the public or the authorities to undertake a proper review of an EIR of the magnitude of those produced in the assessment, for example, of the application by Eskom for authorisation of its Pebble Bed Modular Reactor, ${ }^{63}$ or the Wild Coast N2 Toll Road, ${ }^{64}$ in a mere 105 days in total. ${ }^{65}$ In all likelihood, deadlines will not be met. ${ }^{66}$

What then? Will this result in court action to compel either a response from the authority or, if it is a dilatory I\&AP that has indicated that it will respond, an order ruling that an I\&AP is out of time? Regulation 9(2) merely requires the competent authority, if it is an organ of state, to "notify the Minister or MEC" that it is unable to meet any time-frame. No indication is given of what steps the Minister or MEC will be entitled to take, or should take, in the circumstances. Will the court be asked to compel the authority to make a decision without comment by I\&APs on the report if the deadlines have been missed or without proper consideration by the authority if it is out of time? The new Regulations do not deal with this, and there is nothing to suggest that they will not have similar failings that will lead to similar delays in the finalisation of the new assessment processes.

\subsection{Time-frames after submission of an environmental impact assessment report}

The new Regulations set out clear time-frames within which the process is to be completed once the public participation process has been completed, specialist

\footnotetext{
See, for instance, DEAT $2008 \mathrm{http}: / /$ bit.ly/g5YXCz.

See nn 68 and 77.

This is the total provided by Regs 35(1) and 36(1), but excluding the additional time allowed if a report has been referred for specialist review under Reg 35(1)(b).

66 In the two examples cited, the final reports submitted were the culmination of years of study, public participation and complex scientific investigation. It is unreasonable to expect the authority to deal with such reports in only fifteen weeks, given their resources. They too may need to buy in expertise and to commission peer-review reports that may conceivably take as long to prepare as the report submitted. While it is possible for authorities to request more information - which will provide more time - this is not something that can be relied upon.
} 
studies have been undertaken and the final report submitted for consideration. The Regulations provide:

Consideration of environmental impact assessment reports

35. (1) The competent authority must, within 60 days of receipt of an environmental impact assessment report, in writing -

(a) accept the report;

(b) notify the applicant that the report has been referred for specialist review in terms of section 24 I of the Act;

(c) request the applicant to make such amendments to the report as the competent authority may require for acceptance of the environmental impact assessment report; or

(d) reject the report if it does not comply with regulation 32(2) in a material respect.

(2) (a) An environmental impact assessment report that is rejected in terms of sub-regulation (1)(d) may be amended and resubmitted by the EAP.

(b) On receipt of the amended report, the competent authority must reconsider the report in accordance with sub-regulation (1).

\section{Decision on applications}

36. (1) A competent authority must within 45 days of acceptance of an environmental impact assessment report in terms of regulation 35 or, if the report was referred for specialist review in terms of section 24 I of the Act, within 45 days of receipt of the findings of the specialist reviewer, in writing -
(a) grant authorisation in respect of all or part of the activity applied for; or
(b) refuse authorisation in respect of all or part of the activity.

(2) To the extent that authorisation is granted for an alternative, such alternative must for the purposes of sub-regulation (1) be regarded as having been applied for.

(3) On having reached a decision, the competent authority must comply with regulation $10(1)$.

Aside from the capacity ${ }^{67}$ of the authorities in the different provinces to deal with complex reports within the period provided, the potential for delay arises in

\footnotetext{
67 The environmental right contained in S 24 of the Constitution is a non-limited right, and it could consequently be argued that lack of capacity is no excuse.
} 
Regulation 35(1)(b), which allows for specialist review of EIA reports. It is highly desirable that EIA reports containing complex or highly specialist studies be referred for specialist review. However, the period within which such review is to be completed is not fixed; and no guidelines are provided as to what may be considered a reasonable period for such review. The possibility exists that the authority will find itself unable to complete its consideration of an EIA report timeously, and, on the last day possible, will refer the report to a specialist or panel of specialists for review. Once this occurs, the system will grind to a halt and all of the participants will be in the hands of the reviewers. The delays could be excessive, ${ }^{68}$ which would be justified, but also be likely to attract criticism from developers and from EIA detractors within government. Environmental impact assessments might again become a scapegoat for such developers and detractors.

\subsection{Lack of guidance in the public participation process}

The new Regulations give a narrow meaning to the term "participation". The old Regulations made the applicant responsible for the public participation process to ensure that I\&APs and the authority were "given the opportunity to participate in all the relevant procedures contemplated" in the Regulations. This has been spelt out in the new Regulations to mean that notice of the application is given in a variety of forms, and that I\&APs have the right to comment on all written submissions. There is no specific provision relating to the holding of public meetings or direct engagement with the public. The new Regulations merely state that the person conducting the public participation process must ensure that relevant information is

68 The number of specialists qualified and available to undertake review work is limited. There could be long delays in making appointments and the appointees undertaking the work. By way of example, the controversial N2 Wild Coast EIA followed the following time-frames: the environmental scoping report and application for authorisation was submitted in February 2001, the EIA report in February 2003 and a positive ROD issued on 3 December 2003. Over 200 appeals were lodged. Reviewers were appointed on 2 June 2004 and submitted their review report on 29 October 2004, recommending the overturning of the decision of the department. The Minister upheld the appeals and reversed the decision of his department on 9 December 2004. The appeal was determined on a non-scientific technical point that the consultants who undertook the EIA were not independent within the meaning of the Regulations. The review period took nearly five months to complete, a relatively short time given the period of nearly four years to undertake the EIA. 
made available to potential I\&APs and that such parties be given a reasonable opportunity to comment on the application. ${ }^{69}$

"Comment" by I\&APs in this context does not imply consultation with them. Clearly consultation is contemplated in the preamble to NEMA (and in Section 4(f)), which states that "the law should establish procedures and institutions to facilitate and promote public participation in environmental governance". It is in the "consultative process" that the procedure has become bogged down. Consultants and the authorities have differed in their interpretation of the concept but both have generally considered public input as a time-consuming irritant. Interested and affected parties on the other hand have understood participation to go further and to include consultation in decision-making processes, sometimes to the extent that they have seen themselves as the decision-maker.

There needs to be a balance between the two. Participation is impossible without full access to information and it becomes meaningless if the views of participants are not included in the decision-making process, and more so, are seen to be. ${ }^{70}$ The role of the authorities is more complicated. They are both participant and adjudicator in the process and the final arbiter in deciding whether the authorisation is granted. This has not been resolved in the new Regulations: if they are strictly applied, I\&APs will be relegated to spectator status with a right to shout from the sidelines and no more. If they consider that their input has not been properly taken into account, they will have to rely on their right to just administrative action as they have in the past. To this extent, the new Regulations are a retrogressive step in the cause of public participation and the notion of consultative governance implicit in environmental decision-making.

\footnotetext{
69 The obligation to ensure that relevant information be made available can be an onerous task, with extensive implications, but the point remains that "comment" falls short of "consult".

70 The complaint of the I\&APs in the "Gautrain" matter was that despite "hundreds" of meetings with the environmental consultants and the authorities, it was not apparent to them that their comments had been dealt with in the EIA report nor that the report had been changed in accordance with these in any way. Similar criticisms were made in the Pebble Bed Modular Reactor matter (see n 63 above).
} 


\section{Lack of procedural clarity and inflexibility}

The old Regulations did provide for a formal procedure. The lack of prescription of required detail allowed participants considerable flexibility within the procedure. Where there have been failures this was because neither the authorities nor consultants applied the old Regulations correctly. The old Regulations provided clear procedural steps that followed the formal submission of an application form. These were the submission of a plan of study for scoping; the scoping process, the culmination of which was the submission of a scoping report; the submission of a plan of study for the EIA; and the EIA phase, the result of which was an environmental impact assessment report. ${ }^{71}$ The respective plans of study required approval of the authorities and the reports were reviewed by the public and the authorities.

What has happened in practice is that scoping processes have been commixed with the EIA process and the result has been a report that exceeds the requirements of scoping but falls short of the full assessment required of an EIAR. ${ }^{72}$ These reports have been variously termed "advanced scoping reports", or "EIA level scoping" or, best still, "final draft scoping report". The Regulations provided for the issue of an authorisation on submission of the scoping report, if the information contained in the scoping report was sufficient for the consideration of the application without further investigation. The purpose and content of the scoping report is spelt out in Regulation 6(1). It is intended to be an information-gathering exercise, not an evaluation or assessment process. If the latter is required, no decision can be made at this stage and the process must proceed to an EIA. The complexity of the EIA will be determined by the issues identified (which may have required detailed scientific investigation itself) and this is done by the consultant in conjunction with the authority

Hereafter EIAR.

See Weaver et al 1998 "Strengthening the effectiveness of EIA" 300-310. The authors conclude that the "weak link" is the step between scoping and specialist investigation, the latter to include the assessment and evaluation of impacts. We differ with the conclusion drawn. Specialist investigation should be seen as an extension of scoping. It is an expert identification of impacts that together with the perceived impacts (issues) identified by non-expert participants in the process must be included in the scoping report. All impacts, irrespective of their source require assessment and evaluation as a linked but separate process. 
in the preparation of a PSIA. The EIA then proceeds on the basis of defined issues in which the public participates by the review of reports and, if necessary, the submission of its own specialist reports. The complete set of reports, reviews and comments are then considered by the authority in making its decision.

Allowing a scoping report to be expanded to include specialist studies without a proper assessment is irregular. Firstly, it is not provided for in the Regulations; and, secondly, it allows decisions to be made without a proper assessment of the impacts. This lies at the heart of unjustified criticism of the old Regulations. The resultant reports, because they deviate from the Regulations, have allowed scoping reports to masquerade as EIAR's. Criticism of such reports and of the competence of practitioners has been valid. ${ }^{73}$ Similarly, the authorities have been at fault for allowing and even encouraging this deviation from the Regulations.

The new Regulations are more detailed in their procedural requirements, but this will not necessarily resolve the problems encountered in application of the old Regulations. Value judgments will have to be made in the placement of different activities into the two levels of investigation that are called for. Basic assessment is required for the activities set out in Regulation 386. The activities are rated by volume rather than type, and are based on a quantitative rather than a qualitative evaluation. Where throughput or sheer size exceeds the parameters set under Regulation 386, they fall into Regulation 387, and a scoping report and EIA are required. This simplifies matters considerably; but magnitude may not be the key determinant of the most appropriate category or procedure.

The new Regulations attempt to clarify the distinction between scoping and assessment. ${ }^{74}$ If more than a basic assessment is required, then the next level of determination is called for. This requires both scoping and assessment as part of an

73 This has been blamed on the lack of any certification system for practitioners. There has been a rapid growth in the market for EIA practitioners but no professional body to ensure that they have the qualifications and competence required for the challenging task of managing an EIA process and writing an acceptable report. See DEAT (2004) Environmental Impact Reporting Series 14 and 15 ,

74 The objection might be made that the distinction between "basic" and "full" assessment is artificial, but discussion of this falls outside of the scope of this article. 
integral process. There is no provision for the grant of an authorisation after scoping. ${ }^{75}$ This resolves the problems encountered in the application of the old Regulations. Problems may arise, however, when a particular activity falls into the category for which a basic assessment is sufficient, but, as the complexities of the issue unfold, the authority finds itself unable to make a decision on the information supplied. The Regulations allow the authority to call for a scoping report and assessment in such a case. In making such a decision, considerable technical skill and experience will be required. It is in this area that the authorities may lack capacity and sufficient expertise. This provision in the Regulations may allow the authority to buy time by referring an application to a more complex level of study.

\section{Appeals}

Once the process has been completed, the authorities make a decision. Any party aggrieved by the decision has a right of appeal to the Minister within thirty days of notification of the applicant by the authorities of its decision. It is here that matters go awry. The old Regulations did not require either the authority or the applicant to notify I\&APs of the decision. Theoretically, if the applicant remained silent, the thirtyday period would pass and an appeal by any party would become out of time. Furthermore, the Regulations were silent on the right of a party to respond to an appeal filed by an aggrieved person. The first problem was usually addressed by the authorities requiring of the applicant in the ROD that registered I\&APs be notified of the decision and that this be published in the press. The second problem remains unresolved and invites court intervention to be heard, especially if a new matter is introduced in the appeal documentation - there being nothing in the Regulations to prevent this. Simple amendments to the old Regulations could easily have resolved this shortcoming.

The new Regulations provide for a comprehensive appeal procedure that is consistent with the principles of administrative justice. Clear time-frames are set out for the giving of notice of intention to appeal (ten days from notification of the

This could be seen as odd, if scoping shows that there are no significant issues to be assessed. Probably the thinking is that in such a case the matter would not have proceeded beyond the basic assessment stage. 
decision), the filing of the grounds of appeal and supporting documentation (within thirty days of the lodging of the notice of intention to appeal) and responses thereto (within thirty days of notification of the date upon which the appeal documentation becomes available for scrutiny). All of these time limits may be extended by the Minister or MEC on good cause.

Importantly, the Minister or MEC, with whom the appeal is lodged, may appoint an appeal panel to make recommendations. This is a positive step, as it will bring a greater degree of independence to decisions on the merits of the application. Although this was possible under the old Regulations (read with NEMA), it was seldom done.

\section{The quality and independence of environmental impact assessment reports and their authors}

This has not been addressed directly in the new Regulations. Independence of consultants (now termed EAPs) was a requirement under the old Regulations and, although not defined in the old Regulations themselves, guidelines as to what constitutes independence were published by the Department of Environmental Affairs and Tourism ${ }^{76}$ and were generally applied. ${ }^{77}$ The new Regulations take the question of independence no further. For so long as the applicant pays the fees of

\footnotetext{
Hereafter DEAT.

The challenge to the independence of Bohlweki Environmental (Pty) Ltd, the consultants that undertook the EIA for the Wild Coast N2 Toll Road, resulted in the setting aside of the authorisation and ROD by the Minister of Environmental Affairs and Tourism. This was after the Minister commissioned an independent review of the decision by specialists. The Minister concluded that the failure to appoint an "independent consultant" in accordance with the peremptory requirements of Reg 3(1)(a) of the old Regulations resulted in the EIA process being fatally flawed. Reg 3(2) of the old Regulations provides that if the requirement for the independence of the consultant under Reg 3(1) is not complied with, the application is "regarded to have been withdrawn". It followed, in the Minister's reasoning, that S 22(2) of the ECA effectively provided that the purported authorisation could not be validly issued in the light of the fact that the reports considered were compiled by an entity that did not meet the requirements of the old Regulations for independence. Consequently, the Minister had no legal option but to uphold the appeals and to set aside the decision of 3 December 2003 to grant the South African National Roads Agency Limited authorisation to proceed with the construction of the N2 Wild Coast Toll Road. The lack of independence related to a financial interest of the chairman (albeit indirectly) of the board of the consultant in one of the members of the consortium making the application, and a shareholding by another applicant in the consultant. See DEAT 2004 http://bit.ly/fbYEOP for the Minister's decision and the review report.
} 
the consultant, there will be a perception of bias, no matter how truly independent, professionally judged, the EAP actually is.

Kidd and Retief ${ }^{78}$ suggest that: "[a]s was the case with the ECA [Environment Conservation Act] requirements, the applicant is required to appoint an environmental assessment practitioner (EAP) to manage the application". They then add that this EAP "must be independent and must meet certain other requirements, including that he or she have expertise in conducting EIAs" and also that he/she must "perform the work relating to the application in an objective manner, even if this results in views and findings that are not favourable to the applicant". ${ }^{79}$ They then suggest that where the "independence of the EAP is reasonably believed to be compromised, the EAP may be disqualified". ${ }^{80}$

As for the quality of the reports, these will continue to be determined by professional ability. This is a combination of academic qualifications and practical experience. The environment is a complex myriad of interlinked components, an understanding of which requires both specialist and general environmental skills, even where the matter appears on its face to be uncomplicated in purely scientific terms. A multidisciplinary approach is needed; but too often, usually because of budgetary constraints, this is not adopted. There are relatively few EAPs who have the requisite combination of academic qualifications and relevant experience. The necessary skills will come to them with time, but this has been delayed by many new practitioners having "bad experiences" and many never proceeding beyond the scoping phase because of the tendency to conflate scoping with assessment. ${ }^{81}$

Kidd and Retief "Environmental assessment" 1005-1006.

Kidd and Retief "Environmental assessment" 1006, referencing Reg 18.

Kidd and Retief "Environmental assessment" 1006, referencing Reg 19.

Something of the confusion that appears to exist in the minds of many people when it comes to the difference between scoping and assessment can arguably be seen in the judgment of the Constitutional Court in Fuel Retailers Association of Southern Africa v Director-General: Environmental Management, Department of Agriculture, Conservation and Environment, Mpumalanga Province 20076 SA 4 (CC), 10H-J, para 8, in which the Court (per Ngcobo J) stated that "a scoping report is an environmental impact report that must be submitted in support of an application for authorisation under section 22(1) of ECA". See Couzens 2008 SAJELP 50. If judges of the Constitutional Court, applying their minds to the issue, can err so grievously, then perhaps it is not surprising that many others do so too. 
Environmental assessment requires a balancing of environmental, social and economic impacts, ${ }^{82}$ both positive and negative, in a way that the benefits derived from a particular development outweigh the costs borne by society, and that the development is sustainable. It is a challenging process that must be undertaken with openness and accountability. The process followed must be trustworthy, managed by credible practitioners, and adjudicated by an authority in which the public has confidence.

In theory, as the former Minister of Environmental Affairs and Tourism (Minister Van Schalkwyk) pointed out in his pre-release account of the new Regulations, ${ }^{83}$ matters are improved in the following ways:

(a) by the re-identification of activities that would be subject to EIA, teasing out the detail absent from the old list and grouping these in nine "thematic areas" which, depending on the schedule in which they appear, determine the level of EIA to be applied (some presently covered activities, for example the development of land greater than three hectares in extent for residential purposes, will be subject to a "basic assessment process", whereas potentially more damaging activities such as power stations will require a "thorough assessment process");

(b) by reducing the number of applications and providing development thresholds, which will result in faster, cheaper processes;

(c) by giving the authorities prescribed response times of fourteen days for purely administrative actions, forty-five days for review of minor reports and between sixty and 105 days for the review of complex reports;

(d) by increasing departmental capacity and competence by running one-day seminars in all nine provinces; and

(e) by the production of site-specific environment management frameworks for certain geographic areas in which activities will be excluded from the EIA requirements.

Per S 2(3) of NEMA, in which it is stated that "[d]evelopment must be socially, environmentally and economically sustainable".

83 DEAT 2006 http://bit.ly/gzGOJ4. 
It remains to be seen whether these "new and improved" Regulations will be matched by new competence within the body of EAPs and the officials charged with the review of their produce. Processes for the registration of EAPs, the setting of standards for practitioners and the development of a professional ethical code are underway. ${ }^{84}$ The presently voluntary "certification" by a "board" that has no legal authority will give way to formal registration of an association under Section $24 \mathrm{H}$ of NEMA. ${ }^{85}$ The degree to which there might be ministerial intervention in such associations is not clear at this stage. The move towards statutory regulation of EIA practice, and its recognition as a profession requiring of its members appropriate qualification as a prerequisite for a licence to practice, is welcomed. It is unlikely that departmental capacity and competence will reach the required levels merely through the holding of one-day seminars on the Regulations, as suggested by the Minister. ${ }^{86}$ The move towards statutory (or at least regulated) minimum levels of qualification for EAPs must be matched by the raising of the bar for qualification of reviewers within the competent authorities at both national and provincial levels. This will require considerable political will and the allocation of significantly improved resources to the relevant government departments that must fulfil this mandate. Environmental departments are presently treated as "poor relatives" in government, as an unwanted responsibility and as an obstacle to service delivery. The new Regulations require competent implementation before their quality can be properly tested. If not, they will fail for the same reason as their predecessor: not because they were inherently lacking, but because they were not properly applied.

\section{Prognosis}

\subsection{Political will}

The success, partial success or failure of the new Regulations will obviously depend largely on political will. It is worth pointing out that "political will", a phrase much bandied about by commentators critical of government, is probably quite often

\footnotetext{
${ }^{84}$ It is beyond the scope of the present article to deal with this aspect of EIA. For a summary of this initiative and its future direction, see the documents posted on the home page of the Interim Certification Board www.eapsa.co.za.

85 See DEAT and ICBEAPSA $2007 \mathrm{http}: / / \mathrm{bit} . l \mathrm{l} / \mathrm{hFn} 6 \mathrm{PI}$.

86 See above in this section.
} 
misunderstood. Where, presumably, government ought to direct its efforts is in the direction desired by its citizenry - at present, it is unlikely that the average person in South Africa prioritises environmental protection over development and economic growth. ${ }^{87}$ As such, it is little surprise that governmental spokespeople often criticise environmental legislation as hampering development ${ }^{88}$ - this is, arguably, itself a reflection of political will. At the same time as government blames environmental legislation for hindering economic growth and, even, prioritises such growth over environmental protection, so it is that government that has put, and continues to put, that legislation into place. This, again arguably, is probably what government should be doing - responding to the political will of the populace, while at the same time taking reasonable, even unpopular, steps that are in the long-term interest of all.

Nevertheless, there are some extremely worrying signs in South Africa today that government might be leaning too far in the direction of prioritising economic growth, instead of balancing this with environmental protection. One example of this lies in the restructuring of ministerial portfolios in the wake of President Jacob Zuma taking office in 2009. This restructuring has seen the breaking up of the portfolios of Environmental Affairs and Tourism; Water Affairs and Forestry; and Minerals and Energy Affairs - with a consequent, somewhat disturbing, redeployment of Ministers.

Minister Van Schalkwyk, under whose tenure the new Regulations discussed in this article were promulgated, is now Minister of Tourism. Former Minister of Water Affairs and Forestry, and then Minister of Minerals and Energy Affairs, Buyelwa Sonjica, is now Minister of Water and Environmental Affairs. Minerals and Energy Affairs are split, with Susan Shabangu the new Minister of Mining. A new Ministry of Agriculture, Forestry and Fisheries has been created, with Tina Joemat-Peterson as Minister.

It must be of some concern, politically, that Sonjica has been made Minister in charge of Environmental Affairs. During her tenure at both Water Affairs and

87 What is meant by this is that the average person in South Africa, with its high unemployment rate and its huge gap between rich and poor, is presently focused more on short-term than long-term goals. An often-heard criticism from environmentalists is that government lacks the political will to enforce environmental laws. It might be however that government is in fact responding to political will in not so enforcing these laws.

88 See, for instance, Couzens and Gumede 2007 SAJELP. 
Forestry and Minerals and Energy Affairs, she apparently promoted the interests of mining over environmental protection. With Water Affairs and Forestry, for instance, her department was instrumental in promoting the construction of the De Hoop Dam, apparently to benefit mining companies, despite seemingly sound environmental objections. ${ }^{89}$ With Minerals and Energy Affairs, her department apparently pressed the interests of mining companies over sound environmental concerns and objections, even those made by the DEAT itself, in the Pondoland area. ${ }^{90}$

\subsection{Mining and environmental assessment}

Historically, the mining industry in South Africa was not subject to EIA requirements - being specifically exempted under the old Regulations. This was extremely problematic, as it must surely be accepted that mining is an industry capable of doing immense environmental damage - it is a purely extractive industry, and can by no stretch of the imagination be described as a sustainable activity. Per Olivier JA in Director: Mineral Development, Gauteng Region v Save the Vaal Environment, ${ }^{1}$ "the application of the [audi alteram partem] rule is indicated by virtue of the enormous damage mining can do to the environment and ecological systems".

The Mineral and Petroleum Resources Development Act, ${ }^{92}$ however, contains a very unusual provision. Section 37 is headed "Environmental management principles" and provides that:

(1) The principles set out in section 2 of the National Environmental Management Act, 1998 (Act 107 of 1998) - (a) apply to all prospecting and mining operations, as the case may be, and any matter relating to such operation; and (b) serve as guidelines for the interpretation, administration and implementation of the environmental requirements of this Act.

(2) Any prospecting or mining operation must be conducted in accordance with generally accepted principles of sustainable development by integrating social, economic and environmental factors into the planning and implementation of prospecting and mining projects in

See Couzens and Dent 2006 PER.

See, for instance, Van der Merwe $2008 \mathrm{http}: / /$ bit.ly/fXM6BN.

19992 SA 709 (SCA) 719B.

28 of 2002 - hereafter MPRDA. 
order to ensure that exploitation of mineral resources serves present and future generations.

What is unusual here is that it was felt necessary to make it explicit that the mining industry be subject to environmental regulation - surely an acknowledgement that the mining industry would otherwise attempt to avoid such regulation. However, the MPRDA still left it to the Minister of Minerals and Energy Affairs to oversee the environmental aspects of mining matters, and to make decisions relevant to environmental authorisation in respect of mining matters.

When the new Regulations came into effect on 1 July 2006, they contained two concessions to the mining industry. Firstly, implementation of the Regulations was delayed until 1 April 2007 for mining operations; and, secondly, the Minister of Minerals and Energy Affairs remained the decision-maker for a limited period. ${ }^{93}$ Subsequent to this, however, it was to become apparent that the mining industry was not content with the situation and that it sought greater autonomy. After apparently extensive negotiations between the Minister of Minerals and Energy Affairs (Minister Sonjica) and the Minister of Environmental Affairs and Tourism (Minister Van Schalkwyk), the National Environmental Management Amendment Act ${ }^{94}$ was promulgated in January $2009 .{ }^{95}$

One of the objects of the Amendment Act is "to empower the Minister of Minerals and Energy to implement environmental matters in terms of the National Environmental Management Act, 1998" in so far as such implementation "relates to prospecting, mining, exploration, production or related activities on a prospecting, mining, exploration or production area". ${ }^{96}$ A further object is to "align environmental requirements" in the MPRDA with NEMA by "providing for the use of one environmental system and by providing for environmental management

The original period was to have been three years, but this provision was overtaken by the events of the promulgation of Act 62 of 2008.

62 of 2008 - hereafter NEMA Amendment.

The Act was signed into existence on 5 January 2009 (GN 22 in GG 31789 of 9 January 2009).

Preamble to NEMA Amendment. 
programmes, consultation with State departments" and other matters. ${ }^{97}$ Included in the category of "other matters" is "exemption from certain provisions of [NEMA]". ${ }^{98}$

It is provided in the definitions section of the Amendment Act (Section 1) that NEMA will be amended to provide that the "Minister" remain the Minister of Environmental Affairs and Tourism "in relation to all environmental matters" except with regard to implementation of environmental legislation (as well as "regulations, policies, strategies and guidelines") relating to mining activities (including prospecting, mining, exploration, production and related activities).

Prior to the Amendment Act, Section 24(1) of NEMA provided that:

In order to give effect to the general objectives of integrated environmental management laid down in this Chapter, the potential impact on the environment of listed activities must be considered, investigated, assessed and reported on to the competent authority charged by this Act with granting the relevant environmental authorisation.

After amendment, Section 24(1) provides that:

In order to give effect to the general objectives of integrated environmental management laid down in this Chapter, the potential consequences for or impacts on the environment of listed activities or specified activities must be considered, investigated, assessed and reported on to the competent authority or the Minister of Minerals and Energy, as the case may be ... [Own emphasis]

The amended sections (italicised above) make it clear that there are now parallel decision-makers in respect of environmental authorisations - one for mining-related decisions, and one for all other decisions.

Section 43 of the Amendment Act substitutes the previous section in NEMA and provides that:

\footnotetext{
97 Preamble to NEMA Amendment.

98 Preamble to NEMA Amendment.
} 
[A]ny person may appeal to the Minister against a decision taken by any person acting under a power delegated by the Minister under this Act or a specific environmental management Act. ${ }^{99}$

This refers to the Minister responsible for Environmental Affairs, but not to a matter concerning a mining-related decision. Compromise, and a potential lifebelt for those seeking increased environmental protection, lies in the appeal procedure. Section 43 provides further that:

[A]ny person may appeal to the Minister against a decision taken by the Minister of Minerals and Energy in respect of an environmental management programme or environmental authorisation. ${ }^{100}$

It must, however, be of grave concern for the potential efficacy of the new Regulations that it is the Minister of Mining that will be responsible for initial authorisations, and that the Minister of Water and Environmental Affairs will play a role only at the appeal stage. Appeals, of course, are by their nature notoriously difficult to win - relying heavily, as they do, on procedural objections.

Recent media reports have suggested that Minister Sonjica, in her new role as Minister responsible for Water and Environmental Affairs, may not be inclined to take a firm stand against mining operations. ${ }^{101}$ An allegedly illegal mine in Mpumalanga, operated by a mining company part-owned by the husband (one Andrew Hendricks) of former Minister of Minerals and Energy Affairs, and former Minister of Water Affairs and Forestry, Lindiwe Hendricks, has been exposed as operating without a water permit for approximately three years. In response to a parliamentary question as to whether her department would take action against the mining operation, Sonjica allegedly averred that it was the responsibility of the Department of Mining to effect such action. ${ }^{102}$

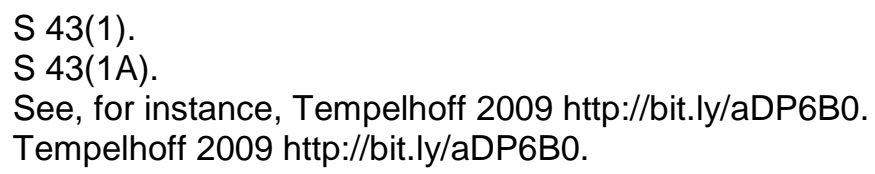




\subsection{The sidelining of the National Environmental Management Act}

While this is hopefully just a matter of a new minister finding her feet, and will not become a trend, it is worrying. In her first major public pronouncement on the issue of EIA, Minister Sonjica ${ }^{103}$ said:

The NEM Amendment Act 62/2008 ... opened the door to a new and improved environmental impact assessment and management regime for South Africa.

That system will move us away from an environmental impact management approach that is solely reliant on EIA to a system where the EIA tools form but one in a variety of instruments to ensure efficiency and effectiveness in environmental impact management.

What is perhaps of most concern about this assertion is that it would seem to presage a major shift away from the philosophy of the new Regulations - even before the opportunity has been taken to test their effectiveness in practice. To put it differently, no sooner has one minister heralded the advent of a new, more effective regulatory system of EIA, than his replacement has indicated that the entire system will not assume the central role it had been expected that it would take, and that it will instead be considered alongside other, non-specified, "tools". This is not, of course, to say that Minister Van Schalkwyk did not presage this approach. In November 2008, while still Minister of Environmental Affairs and Tourism, Minister Van Schalkwyk was quoted as saying that "EIAs should be supplemented by the use of tools such as strategic spatial instruments, bio-regional plans and spatial development and environmental management frameworks". ${ }^{104}$ The approach of expanding the "toolbox" beyond "project level assessment" is therefore not new. What might be new is the emphasis in approach taken by a new minister.

Arguably, allowing the mining industry to become largely "self-regulating" is in conflict with NEMA's principles, which require (at least implicitly) that all applicants for permission to undertake activities that may significantly affect the environment be treated alike. However, where NEMA has been amended to allow such "self-

\footnotetext{
103 Sonjica $2009 \mathrm{http}: / /$ bit.ly/14PIVU.

104 Ensor $2008 \mathrm{http}: / /$ bit.ly/gLjlKO. Van Schalkwyk was giving the opening address at a conference arranged by DEAT to "reflect on 10 years' experience of environmental impact assessments and to begin charting a new EIA strategy and action plan with industry stakeholders".
} 
regulation" it obviously becomes difficult to argue that NEMA is in conflict with itself. A possible conclusion is that NEMA needed to be amended in order to prevent such conflict - but that the statute, as amended, is now in conflict with its original principles.

While no environmentalist would argue that EIA is a perfect tool, it does provide us with arguably the best tool that we have yet found to ensure development considerations do not override environmental protection. It has been said that EIA is "essentially a procedure for facilitating public participation with government authorities in a collective study of the various environmental impacts of proposed actions". ${ }^{105}$ Ultimately, the EIA process does not provide definitive answers. Its aim is to place the environmental decision-maker in a position from which he/she can weigh priorities from an informed perspective before making a decision. If, however, that process of information gathering is itself to be merely one consideration amongst others, then the role of EIA has been seriously lessened.

In 1986, Rabie ${ }^{106}$ wrote that:

[T] he ultimate aim of EIA is that the information revealed in the process should be taken into account during planning and decision-making. This implies that a strategy should be devised, by which the concern for environmental quality would be elevated to one of the goals vying for the attention of decision-makers. Planning and decision-making presuppose the availability of different courses of action and imply the selection of a certain course. The number and range of alternative actions that will be considered will vary depending upon the information made available to the decisionmaker, while priorities would be established according to the societal values as perceived by the decision-maker.

Ultimately, there is nothing in the quote that is out of kilter with the pronouncements of either Ministers Sonjica or Van Schalkwyk more than two decades later. This is reassuring, as it implies that Rabie's hopes were fulfilled and that the seeds he was planting bore fruit. Rabie was at the time suggesting, however, that environmental

Robinson 2006 SAJELP 96.

Rabie 1986 SA Public Law 19. 
considerations be elevated in decision-making - there is a danger now, one of emphasis, that the fruit might be seen as overripe and as less important. ${ }^{107}$

\section{Conclusion}

Time will tell whether the new EIA Regulations that were the political solution of one minister will yet become the target of another, as developers garner the support of cabinet members in their branding of environmental controls as "anti-development". While it is probably too soon to panic, it appears that we might be entering into a crucial phase in the development of South African environmental law - it is going to require extreme vigilance (even activism) from environmental lawyers if, out of the current maelstrom of case law, statute law, politics and policy, a proper balance amongst economic growth, social development and environmental protection is to emerge. There is a great danger that the role and place of the new Regulations will be determined by reality and pragmatism in a debate in which the new Regulations will be little more than background noise. If this fear becomes reality, then the principles of NEMA, which do so much to make South Africa's statutory environmental regime the envy of environmental lawyers elsewhere will be well and truly missing.

Bray $^{108}$ writes that NEMA was "the first 'umbrella' national legislation which endeavours to establish an IEM framework which, in time, will transform and coordinate most of the currently diverse and fragmented sectors of the environment". She also warns, however, that:

$[\mathrm{T}]$ here are many indications that development and environmental policies and legislation are still tackled separately and this has grave implications for the integration and co-ordination of development and environment, and the ultimate achievement of sustainable development. The danger of environmental issues (including environmental management) becoming marginalised as politically urgent developmental issues are resolved for short-term gain, is still imminent.

\footnotetext{
107 While it would be difficult to argue at this stage, and before the new Regulations have been given time to work, that rights have been eroded, it is our contention that rights are presently at least threatened with erosion.

108 Bray 1999 SAJELP 1.
} 
Unfortunately, Bray's words ${ }^{109}$ are as resonant at the time of writing of this article as they were prescient a decade ago.

109 From a decade before the publication of this present dedicated issue of the PER. 


\section{Bibliography}

Aucamp 2009 Environmental Impact Assessment

Aucamp PJ Environmental Impact Assessment: A Practical Guide for the Discerning Practitioner (Pretoria Van Schaik 2009)

Bray 1999 SAJELP

Bray E "Focus on the National Environmental Management Act: Co-operative governance in the context of the National Environmental Management Act 107 of 1998" 1999 SAJELP 1-12

Couzens 2008 SAJELP

Couzens E "Filling Station Jurisprudence: Environmental Law in South African Courts and the Judgment in Fuel Retailers Association of Southern Africa $v$ Director-General: Environmental Management, Department of Agriculture, Conservation and Environment, Mpumalanga Province, and Others 2007 (6) SA 4 (CC)" 2008 SAJELP 23-56

Couzens and Dent 2006 PER

Couzens E and Dent M "Finding NEMA: The National Environmental Management Act, the De Hoop Dam, conflict resolution and Alternative Dispute Resolution in environmental disputes" 2006 PER 9(3) 2-51

Couzens and Gumede 2007 SAJELP

Couzens E and Gumede K "Losing NEMA: Wildlife and Environmental Society of South Africa $v$ MEC for Economic Affairs, Environment and Tourism, Eastern Cape, and Others 20056 SA 123 (E) Case no. 28761/05, TPD, decided on 23 June 2006" 2007 SAJELP 125-134 
Field 2005 SALJ

Field T "Public participation in environmental decision-making: Earthlife Africa

(Cape Town) v Director General: Department of Environmental Affairs and Tourism" 2005 SALJ 748-765

Glazewski Environmental Law

Glazewski J Environmental Law in South Africa (Durban LexisNexis 2005)

IUCN et al Caring for the Earth

IUCN et al Caring for the Earth: A Strategy for Sustainable Living (IUCN, United Nations Environment Program and World Wide Fund for Nature Gland 1991)

Jain et al Environmental Impact Analysis

Jain RK et al Environmental Impact Analysis: A New Dimension in DecisionMaking (Van Nostrand Reinhold New York 1977)

Kidd Environmental Law

Kidd M Environmental Law (Cape Town Juta 2008)

Kidd and Retief "Environmental assessment"

Kidd $\mathrm{M}$ and Retief $\mathrm{F}$ "Environmental assessment" in Strydom HA and King ND (eds) Fuggle and Rabie's Environmental Management in South Africa $2^{\text {nd }}$ ed (Juta Cape Town 2009) 971-1047

Peckham 1997 SAJELP

Peckham B "Environmental impact assessments in South African law" 1997 SAJELP 113-133 
Rabie 1986 SA Public Law

Rabie A "Strategies for the implementation of environmental impact assessment in South Africa" 1986 SA Public Law 18-33

Ridl 1994 SAJELP

Ridl J "IEM: Lip-service and licence?" 1994 SAJELP 61-83

Ridl, Carnelley \& Couzens 2005 SAJELP

Ridl J, Carnelley M \& Couzens E “(Bio)Tracing Poor Exemptions: South

Durban Community Environmental Alliance (SDCEA) v Head of Department:

Department of Agriculture and Environmental Affairs and Others 2003 (6) SA 631 (D)" 2005 SAJELP 151-171

Robinson 2006 SAJELP

Robinson NA "Environmental impact assessments: Essential methodology or paper tiger?" 2006 SAJELP 97-104

Van Schalkwyk Mail \& Guardian 21

Van Schalkwyk M "Simpler. Better. Greener?" Mail \& Guardian 21 Apr 200621

Ward Biological Environmental Impact Studies

Ward DV Biological Environmental Impact Studies: Theory and Methods (Academic Press New York 1978)

Weaver et al "Strengthening the effectiveness of EIA"

Weaver A et al "Strengthening the effectiveness of EIA in South Africa" (Paper presented at the International Association for Impact Assessment - South Africa Conference Cathedral Peak 1998) 300-310 


\section{Register of legislation}

Environment Conservation Act 73 of 1989

National Environmental Management Act 107 of 1998

National Environmental Management Amendment Act 62 of 2008

Mineral and Petroleum Resources Development Act 28 of 2002

\section{Register of government publications}

GN R1182 in GG 18261 of 5 September 1997

GN R1183 in GG 18261 of 5 September 1997

GN R1184 in GG 18261 of 5 September 1997

GN R385 in GG 28753 of 21 April 2006

GN R386 in GG 28753 of 21 April 2006

GN R387 in GG 28753 of 21 April 2006

GN 657 in GG 28854 of 19 May 2006

GN 22 in GG 31789 of 9 January 2009

Council for the Environment Integrated Environmental Management

Council for the Environment Integrated Environmental Management in South Africa (Joan Lotter Publications Pretoria 1989)

DEA Guidelines

DEA Integrated Environmental Management Guideline Series (DEA Pretoria 1992)

DEAT Environmental Impact Reporting

DEAT Environmental Impact Reporting: Integrated Environmental Management Information Series 0-16 (DEAT Pretoria 2004) 


\section{Register of cases}

Director: Mineral Development, Gauteng Region v Save the Vaal Environment 1999 2 SA 709 (SCA)

Fuel Retailers Association of Southern Africa v Director-General: Environmental Management, Department of Agriculture, Conservation and Environment, Mpumalanga Province 20076 SA 4 (CC)

\section{Register of Internet sources}

DEAT 2004 http://bit.ly/fbYEOP

DEAT 2004 Final N2 Wild Coast decision http://bit.ly/fbYEOP [date of use 23 Feb 2011]

DEAT 2006 http://bit.ly/gzGOJ4

DEAT 2006 New regulations to speed up EIA processes http://bit.ly/gzGOJ4 [date of use 23 Feb 2011]

DEAT 2006 http://bit.ly/hbqAP8

DEAT 2006 Presentation on Revised National Environmental Management Act: Environmental Impact Assessment Regulations http://bit.ly/hbqAP8 [date of use 23 Feb 2011]

DEAT and ICBEAPSA 2007 http://bit.ly/hFn6PI

DEAT and ICBEAPSA 2007 Towards the establishment of a registration authority for environmental assessment practitioners in South Africa consultative process with key stakeholders: Process update and invitation to comment on: Draft proposal for the establishment of a Registration Board for Environmental Assessment Practitioners of South Africa http://bit.ly/hFn6PI [date of use 22 Feb 2011] 
DEAT 2008 http://bit.ly/g5YXCz

DEAT 2008 Draft environmental impact assessment report for a $400 \mathrm{MW}(\mathrm{t})$ Pebble Bed Modular Reactor demonstration power plant http://bit.ly/g5YXCz [date of use 23 Feb 2011]

Ensor $2008 \mathrm{http}: / / \mathrm{bit} . l y / g L j l K O$

Ensor L "Environmental assessments 'easily bought"' Business Day 26 Nov 2008 http://bit.ly/gLjlKO [date of use 23 Feb 2011]

LED SALGA 2010 http://bit.ly/hBg7HU

LED SALGA 2010 Document: Environmental Impact Assessment (EIA)

Regulations $2010 \mathrm{http}: / /$ bit.ly/hBg7HU [date of use 23 Feb 2011]

MacLeod 2006 http://bit.ly/if07ZJ

MacLeod F "Mbeki joins assault on green laws" Mail \& Guardian Online 7 Aug 2006 http://bit.ly/if07ZJ [date of use 23 Feb 2011]

Sonjica 2009 http://bit.ly/14PIVU

Sonjica BP Speech on the environment budget vote 18 Jun 2009

http://bit.ly/14PIVU [date of use 23 Feb 2011]

Tempelhoff 2009 http://bit.ly/aDP6B0

Tempelhoff E "Sonjica trek skouers op oor onwettige mynbou" Volksblad 23 Sept 2009 http://bit.ly/aDP6B0 [date of use 23 Feb 2011]

Van der Merwe 2008 http://bit.ly/fXM6BN

Van der Merwe C "MRC granted right to mine along SA's Wild Coast" Creamer Media's Mining Weekly 4 Aug 2008 http://bit.ly/fXM6BN [date of use 23 Feb 2011] 
Van Schalkwyk 2006 http://bit.ly/fsdco5

Van Schalkwyk M 2006 Environmental protection: Quicker, simpler, better new EIA regulations for South Africa http://bit.ly/fsdco5 [date of use 23 Feb 2011]

\section{List of abbreviations}

ADR

DEA

DEAT

EAP

ECA

EIA

EIAR

EIR

I\&APs

ICBEAPSA

IEM

IUCN

LED SALGA

MEC

MPRDA

NEMA

PER

ROD

SAJELP

SALJ
Alternative dispute resolution

Department of Environment Affairs

Department of Environmental Affairs and Tourism

Environmental assessment practitioner

Environment Conservation Act

Environmental impact assessment

Environmental impact assessment report

Environmental impact report

Interested and affected parties

Interim Certification Board for Environmental

Assessment Practitioners of South Africa

Integrated environmental management

International Union for Conservation of Nature

South African LED Network South African Local

Government Association

Member of the Executive Council

Mineral and Petroleum Resources Development Act

National Environmental Management Act

Potchefstroomse Elektroniese Regsblad

Record of decision

South African Journal of Environmental Law and

Policy

South African Law Journal 